\title{
First year of practical experiences of the new Arctic AWIPEV- COSYNA cabled Underwater Observatory in Kongsfjorden, Spitsbergen
}

\author{
Philipp Fischer $^{1}$, Max Schwanitz ${ }^{1}$, Reiner Loth ${ }^{2}$, Uwe Posner ${ }^{3}$, Markus Brand ${ }^{1}$, and Friedhelm Schröder ${ }^{4}$ \\ ${ }^{1}$ Alfred-Wegener-Institut Helmholtz Centre for Polar and Marine Research, Centre for Scientific Diving \\ at the Biological Station Helgoland, Kurpromenade 211, 27498 Helgoland, Germany \\ ${ }^{2}$ loth-engineering GmbH, Lochmühle 1, 65527 Niedernhausen, Germany \\ 3 -4H-JENA engineering GmbH, Mühlenstr. 126, 07745 Jena, Germany \\ ${ }^{4}$ Helmholtz-Zentrum Geesthacht, Institut für Material- und Küstenforschung, \\ Max-Planck-Straße 1, 21502 Geesthacht, Germany \\ Correspondence to: Philipp Fischer (philipp.fischer@awi.de)
}

Received: 2 July 2016 - Discussion started: 12 July 2016

Revised: 10 January 2017 - Accepted: 10 February 2017 - Published: 4 April 2017

\begin{abstract}
A combined year-round assessment of selected oceanographic data and a macrobiotic community assessment was performed from October 2013 to November 2014 in the littoral zone of the Kongsfjorden polar fjord system on the western coast of Svalbard (Norway). State of the art remote controlled cabled underwater observatory technology was used for daily vertical profiles of temperature, salinity, and turbidity together with a stereo-optical assessment of the macrobiotic community, including fish. The results reveal a distinct seasonal cycle in total species abundances, with a significantly higher total abundance and species richness during the polar winter when no light is available underwater compared to the summer months when $24 \mathrm{~h}$ light is available. During the winter months, a temporally highly segmented community was observed with respect to species occurrence, with single species dominating the winter community for restricted times. In contrast, the summer community showed an overall lower total abundance as well as a significantly lower number of species. The study clearly demonstrates the high potential of cable connected remote controlled digital sampling devices, especially in remote areas, such as polar fjord systems, with harsh environmental conditions and limited accessibility. A smart combination of such new digital "sampling" methods with classic sampling procedures can provide a possibility to significantly extend the sampling time and frequency, especially in remote and difficult to ac-
\end{abstract}

cess areas. This can help to provide a sufficient data density and therefore statistical power for a sound scientific analysis without increasing the invasive sampling pressure in ecologically sensitive environments.

\section{Introduction}

Kongsfjorden $\left(78^{\circ} 55^{\prime} \mathrm{N}, 11^{\circ} 56^{\prime} \mathrm{E}\right)$ on the western coast of Spitsbergen (Fig. 1) is described as one of the best studied polar fjord systems in the Arctic (Wiencke, 2004). The $20 \mathrm{~km}$ long ecosystem opens without a sill in a westerly direction toward the Fram straight (Hop et al., 2002) and is alternatively penetrated by warm saline Atlantic water masses from the West Spitsbergen Current, by cold less saline Arctic water from the East Spitsbergen Current, or a mixture of both (Cottier et al., 2005). This bi-modal hydrographic situation leads to a complex spatio-temporal pattern in the fjord hydrography with an occasionally more Atlantic and in other instances more Arctic characteristic with respect to the water masses, even in the inner fjord system (Svendsen et al., 2002). Due to an increased advection rate of warmer Atlantic water masses in the fjord systems over the last decade (Cottier et al., 2005), the first signs of an overall warming of the fjord system have been observed, with an overall decrease in seasonal ice coverage (Walczowski et al., 2012), signifi- 


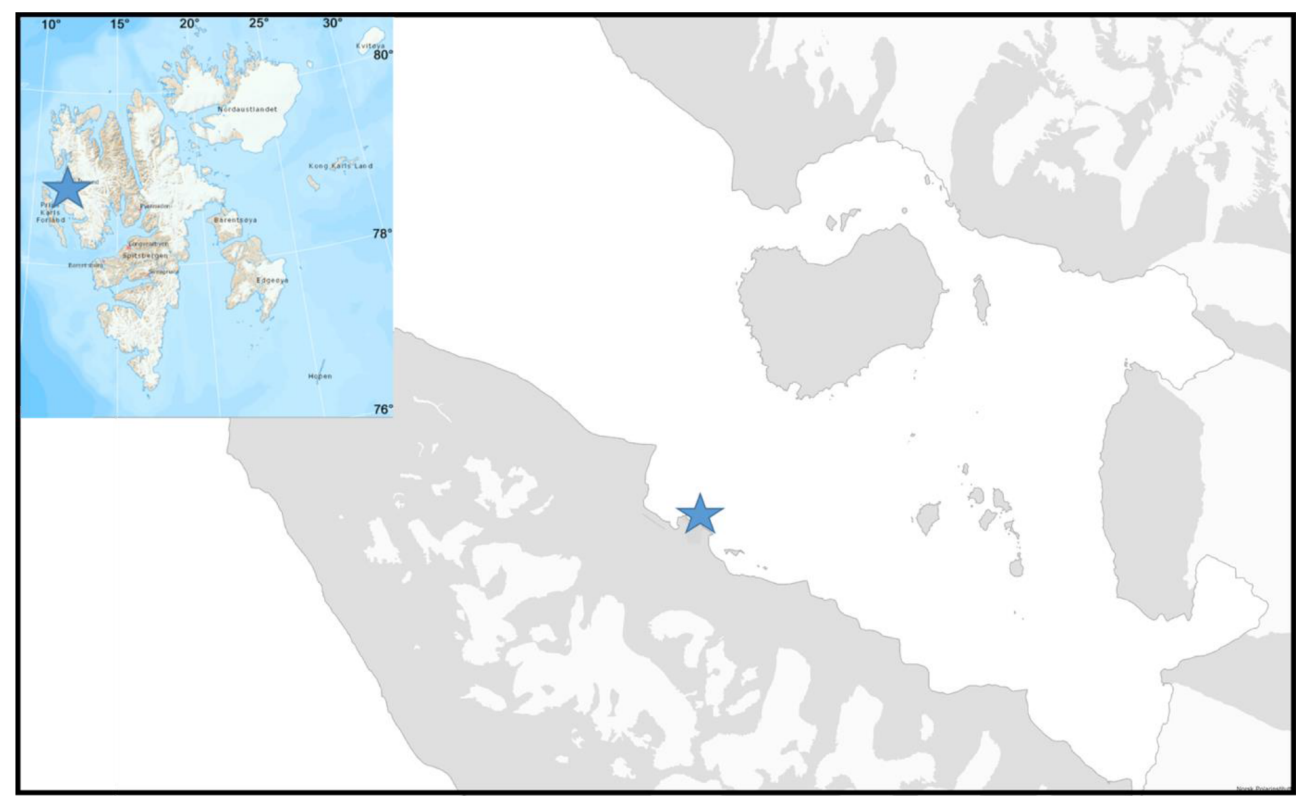

Figure 1. Spitzbergen with Kongsfjorden ( $\star$ in the small inlay panel in the upper left corner) and the location of NyÅlesund in Kongsfjorden ( $\star$. Source: Norwegian Polar Institute (2014), 2017.

cant changes in the phytoplankton community (Hegseth and Tverberg, 2013; Willis et al., 2006), changes in the depth distribution of macroalgae in the shallow waters (Bartsch et al., 2016) and in the macrozoobenthos community (Parr at al., 2015), as well as an increase in turbidity due to increased meltwater runoff from the glaciers (Peterson et al., 2002; Bartsch et al., 2016). Although Renaud et al. (2011) and Voronkov et al. (2013) recently started to study the foodchain length, trophic levels, and the main feeding groups in Kongsfjorden, our knowledge of the temporal and spatial dynamics of the higher trophic levels of the food web is still extremely limited (Stempniewicz et al., 2007). Therefore, important knowledge gaps such as a lack of quantitative data on production, abundance of key prey species, and the role of advection in the biological communities in the fjord still exist (Hop et al., 2002).

Such knowledge, however, is mandatory for a better understanding of this polar fjord system and potentially to use it as a model system for future Arctic change scenarios under the pressure of global warming. The most comprehensive review thus far of the occurrence and higher trophic level species in the Kongsfjorden ecosystem has been performed by Hop et al. (2002) and revealed approximately 34 zooplankton taxa, between 29 and 396 macrozoobenthos species, as well as approximately 30 fish species in the fjord system in total, depending on the type of substratum. Most of these data have been sampled during intense summer campaigns with shipsupported sampling methods or by occasional scuba diving operations at different sites of the fjord. Although these datasets are highly valuable, they are mainly restricted to the polar summer when light is available and sampling can be performed on a regular basis. A systematic year-round assessment of the fjord community, especially of the shallow water habitats, which are well known as most important as spawning, hatching, and nursery grounds for juvenile specimens (Fischer and Eckmann, 1997a, b; Werner, 1977), is missing.

Thorough assessments especially of higher tropic levels such as fish and macroinvertebrates are demanding already in northern temperate non-polar waters because of the required logistics, methods, and manpower (Wehkamp and Fischer, 2013a, b, c). In Arctic waters with the even harsher conditions with respect to low winter temperatures, seasonally limited daylight availability and a partial or complete ice coverage, longer-term and year-round assessments especially in shallow coastal areas are almost completely lacking. Furthermore, in several hard bottom fjord systems, such as the Kongsfjorden system, the shallow water areas are relatively inaccessible by trawling with larger vessels due to a complex and highly structured benthic habitat, with a mixture of rocky bottom and ice-rafted pebbles and stones (Jørgenson and Gulliksen, 2001). Therefore, most available studies are temporally restricted to the summer months and the open or deeper water bodies.

In the present study, we present data from a 13month (October 2013 to November 2014) long hydrobiological survey in the sublittoral zone of the Arctic Kongsfjorden at the southern shoreline close to the research village of NyÅlesund at $\mathrm{UMT} 8763953^{\circ} \mathrm{N}, 433992^{\circ} \mathrm{E}$ (Fig. 1). With a 2012 installed cabled underwater observatory (COSYNA@AWIPEV Underwater Observatory - subsequently called UWO), we continuously recorded the main 
hydrological parameters temperature, salinity, $\mathrm{pH}, \mathrm{Chl} a$, and turbidity and additionally made a quantitative analysis of the abundance, species occurrence, and (for selected species) length-frequency distribution of the fish and macroinvertebrate taxa. For the latter assessment, a stereo-optical macrobiota observatory called "RemOS1" (Remote Optical System) was used, specifically designed for long-term exposure and assessments of fish and macroinvertebrate communities in shallow water areas (Fischer et al., 2007b). Data acquisition was conducted year-round, remote controlled with a temporal resolution of $1 \mathrm{~Hz}$ for the hydrological data and with a stereoscopic imaging frequency of $30 \mathrm{~min}$. Parallel to this study, classic fishing campaigns were performed in 2012, 2013, and 2014 in the months June/July and September in the same area with standard fyke nets to provide ground-truth data for the remotely sampled fish data. These fishing data are published in Brand and Fischer (2016) for the years 2012 and 2013. The data for 2014 will be published together with a comparative analysis of the results of the UWO elsewhere (M. Brand, personal communication, 2016).

The present study aims to demonstrate the high potential of remote controlled sensors to quantitatively assess not only hydrological data such as temperature, current, or plankton community with classical CTD (conductivity-temperaturedepth) probes or VPRs (video plankton recorders), but also for the assessment of higher tropic levels such as macroinvertebrates and fish. To the best of our knowledge, there are only a small number of studies and observatories available worldwide that are trying to also assess higher trophic levels with remote controlled optical systems (Aguzzi et al., 2011; Buckland et al., 2005; Fischer et al., 2007b; Wehkamp and Fischer, 2014), and even fewer with regard to quantitative assessments with respect to a specimen's abundances and species-specific length-frequency analysis in an area. Because these technologies will certainly develop and improve over the next years, this study also discusses certain specific requirements and challenges for such systems, especially for shallow water Arctic areas.

\section{Materials and methods}

The UWO was built up in 2012 in the framework of COSYNA (Coastal Observing Systems of the Northern and Arctic Seas). The system comprises a land-based FerryBox system equipped with various hydrographic sensors (Table 1) receiving water from a remote controlled underwater pump station at $11 \mathrm{~m}$ water depth. Additionally, a cable connected (fibre-optic and $240 \mathrm{~V}$ power) underwater node (Fig. 2) was installed close to the pump station at a $11 \mathrm{~m}$ water depth providing power (48 V) and a network (TCP/IP $100 \mathrm{Mbit}$ ) connection to additional in situ sensors. To install or exchange sensor equipment at the node system by divers, the node is equipped with four underwater matable power/ethernet con-

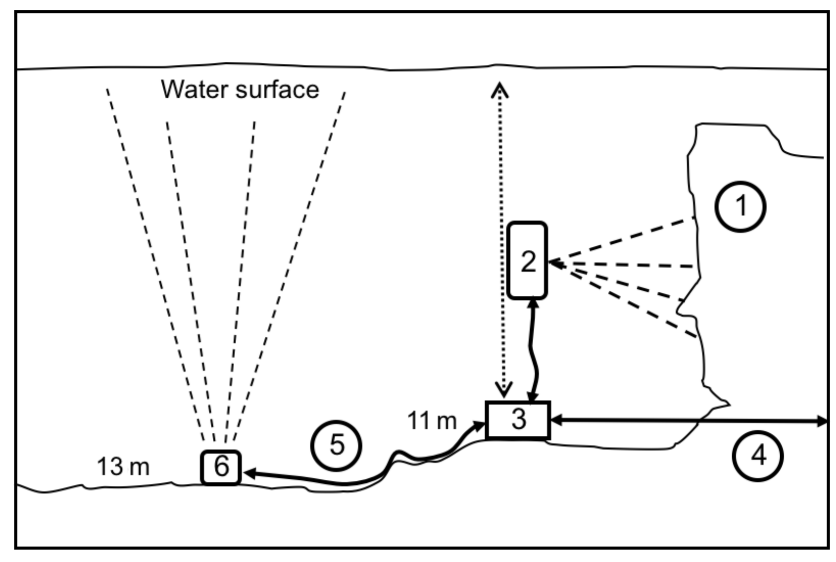

Figure 2. Sketch of the underwater installations with the underwater base station and the vertical profiling unit off NyAlesund. Numbers refer to numbers in the sketch. (1) Steep wall (drop-off) with vertical zonated macrophyte coverage. (2) Vertical profiling sensor carrier with CTD and a stereo-optical imaging device (RemOs1) looking towards the wall. (3) Underwater node with wet-matable plugs. (4) Combined power/fibre-optic cable to land. (5) Combined power/rs232 cable from node to ADCP. (6) ADCP. For details on the single components, see the text.

nectors and two additional underwater matable power/rs232 connectors.

For the experiment described in this study, the node system was equipped with an upward looking ADCP positioned at 13-15 m water depth (depending on the tide cycle), a SBE38 temperature sensor positioned at $11-13 \mathrm{~m}$ water depth (depending on the tide cycle), and a vertical profiling sensor carrier. The profiling sensor carrier was fully remote controlled via the Internet and was operated year-round from October 2013 to November 2014 from Germany. It was equipped with a CTD for the assessment of the main hydrographical parameters and the RemOS1 stereo-optical camera system (Fischer, 2017; Fischer et al., 2007b; Wehkamp and Fischer, 2014) for macrobiota assessments. Using the stereooptic sensor, we assessed the macrobiota, jellyfish, and fish community along the vertical depth profile from $11 \mathrm{~m}$ water depth to the surface with the sensors looking from a distance of about $2.5 \mathrm{~m}$ towards a steep wall that reached from $11 \mathrm{~m}$ of water depth to $3 \mathrm{~m}$ below the mean sea level (Fig. 2). The upper part of the wall was dominated by brown algae of the type of Alaria esculenta, the lower part by Saccharina latissima and the two red algal species Phycodryis rubens and Ptilota gunneri. Using the vertical profiling unit, we conducted a 1-year continuous stereo-optical survey of the fish and the macrozoobenthos community in five depth strata $(11-9,9$ $7,7-5,5-3$, and $3 \mathrm{~m}$ from the water surface). The stereooptical system and the CTD probe were remotely positioned every day between 11:00 and 13:00 $\mathrm{h}$ in one of the five depth layers, with the exact depth being calculated as the distance from the bottom. This means that the effective water depth 
Table 1. Sensors attached to the COSYNA@AWIPEV UWO at UMT $8763953^{\circ} \mathrm{N}, 433992^{\circ}$ E. The FerryBox has its water inlet at a fixed depth of $11 \mathrm{~m}$ below mean sea level (http://vannstand.no/index.php/nb/english-section/sea-level-data). The RemOs1 system is profiling from $11 \mathrm{~m}$ water depth to the surface (for further descriptions, see the text).

\begin{tabular}{|c|c|c|c|}
\hline Sensor carrier & Sensor type & Water depth & Sensor unit manufacturer \\
\hline FerryBox & $\begin{array}{l}\text { Water temperature }\left({ }^{\circ} \mathrm{C}\right) \\
\text { Conductivity }\left(\mathrm{ms} \mathrm{m}^{-1}\right) / \text { salinity }(\mathrm{PSU})^{1} \\
\text { Oxygen }(\%) \\
\mathrm{Chl} a\left(\mathrm{mg} \mathrm{m}^{3}\right) \\
\text { pH } \\
\text { Turbidity (FTU) }\end{array}$ & $11 \mathrm{~m}$ & $\begin{array}{l}\text { SBE45 } \\
\text { SBE45 } \\
\text { Anderra } \\
\text { Cyclops } \\
\text { Meinsberg } \\
\text { Seapoint }\end{array}$ \\
\hline Underwater node & Current (ADCP Teledyne Workhorse $600 \mathrm{kHz}$ ) & $13 \mathrm{~m}$ & Teledyne \\
\hline Underwater node & $\begin{array}{l}\text { Stereo-optical imaging system RemOs } 1 \\
\text { Pressure (dbar) } \\
\text { Water temperature }\left({ }^{\circ} \mathrm{C}\right)\end{array}$ & Profiling $^{2}$ & Fischer et al. (2007) \\
\hline Underwater node & $\begin{array}{l}\text { Conductivity }\left(\mathrm{ms} \mathrm{m}^{-1}\right) /{\text { salinity }(\mathrm{PSU})^{1}}^{1} \\
\text { Oxygen }(\%) \\
\text { Chl } a\left(\mathrm{mg} \mathrm{m}^{3}\right) \\
\text { Turbidity (FTU) }\end{array}$ & Profiling $^{2}$ & Sea\&Sun CTD90 \\
\hline
\end{tabular}

${ }^{1}$ Calculated after actual UNESCO procedures. ${ }^{2}$ Between $11 \mathrm{~m}$ water depth and the surface.

changed with the tide cycle for max. $1.5 \mathrm{~m}$, but the system itself had a fixed position above the ground $(1 \mathrm{~m}$ distance from the bottom for the depth stratum 11-9 m, $3 \mathrm{~m}$ distance for the depth stratum 9-7 m, $5 \mathrm{~m}$ distance for the depth stratum 5$7 \mathrm{~m}, 7 \mathrm{~m}$ distance for the depth stratum 3-5 m, and $9 \mathrm{~m}$ distance for the depth stratum 3-0 m). The daily target depths were selected randomly for each week such that all of the depth strata were sampled once per week for $24 \mathrm{~h}$. Missing depths, e.g. because of system or connection problems to the underwater observatory, were repeated on the weekend. The system was positioned for $24 \mathrm{~h}$ at the selected depth stratum and made stereoscopic images every $30 \mathrm{~min}$. In parallel, all other in situ and FerryBox sensors recorded with a frequency of $1 \mathrm{~Hz}$. The image pairs and all the hydrographic data were transferred automatically via the Internet to Germany for further daily processing. All hydrographic data were automatically quality controlled by automated procedures, flagged as good, probably good, and bad, and stored at a central data server in Geesthacht, Germany, under an open-access policy at http://codm.hzg.de/codm/. For our study, only the data with the quality flags probably good and good were used. Based on these data, we analysed the temporal succession of the shallow water fish, jellyfish, and macrozoobenthos community in this kelp-dominated shallow water Arctic habitat in Kongsfjorden. Organisms on the stereoscopic images were analysed in a two-step procedure following the routines described in Wehkamp and Fischer (2014). The 48 stereoscopic image pairs of each day were first scanned manually for the presence of organisms. This scanning was performed with image analysis software that presented the left image of the stereoscopic pair for at least $5 \mathrm{~s}$ on a $21^{\prime \prime}$ high-resolution computer screen. Only two persons did this basic analysis step over the entire year and thoroughly counterchecked their object findings. During this first step, all the specimens found on an image were counted and pre-classified into the categories fish, jellyfish, appendicularia, pelagic crustacean, benthic crustacean, pteropods, and chaetognats. Organisms that could not be classified into one of these categories were classified as "others". The analyser (the person who did the analysis) had the possibility of increasing or decreasing the image brightness or of enhancing the contrast by a single mouse click quickly. The possibility of such a rapid preprocessing of the 48 stereoscopic image pairs was revealed to be most important because 48 image pairs were produced every day year-round. This rapid assessment procedure allowed a first analysis of all the images per day within approximately $15 \mathrm{~min}$, so that a quasi-online overview of the actual situation under water in the target area and of the functioning of the monitoring system was achieved within $24 \mathrm{~h}$. With this procedure, problems of the system itself or with the data transfer could be detected fast and could be addressed and solved. With this daily rapid assessment routine, we could achieve an acceptable level of operational stability of the systems with less than 15 unplanned offline days over the entire sampling period of 13 months. Unplanned offline days occurred mainly due to failures in the land-based power support system. During such phases, the underwater part of the system was shut down to avoid hardware damage due to spontaneous and possibly critical voltage fluctuations.

In a second image analysis step, all the images where organisms were detected were rectified, which means that the geometry of the images was corrected to eliminate image dis- 
tortions due to the lens of the camera. This correction was performed with the "stereo_gui" modified MATLAB routine (Wehkamp and Fischer, 2014). After this step, all the objects that were detected in the first image analysis step were measured (standard length in fish, carapax length in macrocrustacea, and max. dimension in all other organisms) and identified as precisely as possible, i.e. to species level in most fish species except for the two cod species Boreogadus saida and Gadus morhua, which were not distinguished properly on the images. Furthermore, amphipoda or appendicularia were only identified to the class level.

Because we had a clearly restricted water volume that was assessed by the camera system (volume between the camera and the vertical wall), we calculated the "catch per unit effort" of the system by summarizing all the individuals found on the images per $24 \mathrm{~h}$ and depth stratum. These CPUE $\times 24 \mathrm{~h}^{-1}$ data were used as the basis for all further calculation. We did not recalculate these data on a defined water volume (which is possible) to avoid confounding calculations between benthic organisms living on the two-dimensional bottom or the surface of the algae and planktonic organisms living in the three-dimensional water column.

Length-frequency measurements on the threedimensional-image pairs were performed pooled for each month for the cod species (mainly Gadus morhua), the common sea spiders (Hyas araneus), the two main jellyfish species (Beroe sp. and Aglantha digitale), the appendicularia, and the pteropods (Clione limacina). For these species, all the organisms were measured except for the month when more than 200 specimens occurred within 1 month. In this case, only 200 specimens were measured by randomly selecting over the day of the month.

\section{Results}

\subsection{Habitat description}

The Kongsfjorden shallow water ecosystem is characterized by large kelp beds of different species of macroalgae between 0 and approximately $12-15 \mathrm{~m}$ water depth (Bartsch et al., 2016). The site where the observatory has been set up is, therefore, characteristic of the fjord habitat and provides a highly diverse habitat with a steep wall completely covered with large macroalgae followed by a sandy to muddy slope that begins at approximately $11 \mathrm{~m}$ water depth at the base station of the observatory. The five depth layers covered by the stereo-optical camera system cover the typical vertical gradient of a littoral habitat with a surface near-pelagic habitat (depth range 0-2 m water depth (Fig. 3a), a typical litho-pelagic habitat close to the upper edge of the drop-off (2-4 $\mathrm{m}$ water depth (Fig. 3b), the upper drop-off edge between 4 and $6 \mathrm{~m}$ water depth) with dense horizontal and vertical macrophyte coverage (Fig. 3c), the vertical wall of the drop-off with overhanging structures and grotto-like crevices (water depth 6-8 m, Fig. 3d) and, finally, the lower edge of the drop-off where the wall goes over in the typical benthic habitat with a gentle slope formed by sand and mud at a depth of around $11 \mathrm{~m}$, decreasing further towards north to the centre of the fjord (Fig. 3e).

The observatory technology allows for daily vertical CTD profiles every noon at approximately 12:00 with a sampling frequency of $1 \mathrm{~Hz}$ at a constant profiling speed of $1.5 \mathrm{~m}$ per minute from approximately $10 \mathrm{~m}$ water depth (depending on the tide) to $1 \mathrm{~m}$ below the surface. The FerryBox unity additionally provides complementary hydrographic data from a fixed water depth of $11 \mathrm{~m}$. Figure 4 shows the compiled data for water temperature $\left({ }^{\circ} \mathrm{C}\right)$, salinity (PSU), and turbidity (FTU) from October 2013 to November 2014. The data reveal a distinct seasonal cycle in the water temperature, with the lowest values of approximately $-1.0^{\circ} \mathrm{C}$ in the winter months from October to April and the highest temperatures up to approximately $8^{\circ} \mathrm{C}$ during the summer months, May to September. Most interestingly, however, are the distinct short-term changes in water temperatures even within the individual seasons. These changes spanned ranges of up to $4{ }^{\circ} \mathrm{C}$ within the shortest time periods of a few days both in the summer and in the winter. While the average water temperature, for example, during the middle of December to the end of January was between -0.5 and $+0.5^{\circ} \mathrm{C}$, the water temperatures then suddenly increased within a few days up to $3{ }^{\circ} \mathrm{C}$ and stayed at this comparatively high level until the end of March, when it dropped again to approximately $0.5^{\circ} \mathrm{C}$. In May, the temperatures increased again and reached the highest values of up to $7.7^{\circ} \mathrm{C}$ in the surface layers, which indicates a distinct stratification during this time. In July to September, this stratification dissolved, and the water temperatures were almost equally distributed over the water column. Similar temporal patterns were observed also in salinity (Fig. 4), which indicates that the overall patterns in the water temperature in the shallow littoral zone of the fjord system were also significantly determined by a fast (within days) exchange of water masses that brought either colder and lower saline Arctic water or warmer higher saline water masses even to the shallow fjord areas.

Figure 4 shows the seasonal patterns in turbidity over the water columns. The data indicate that the overall turbidity significantly increased during the seasonal cycle, with higher values from July to September and low values during the rest of the year. However, Fig. 4 also shows a longer lasting local and distinct increase in turbidity close to the bottom in May and June. These high turbidity values during this time are confirmed by both systems, the vertical profiling in situ probe as well as the FerryBox unit.

\subsection{Species community}

Figure 5 (upper panel) shows the sum of individual organisms counted on the images per week for the months October 2013 to November 2014. The average values and stan- 


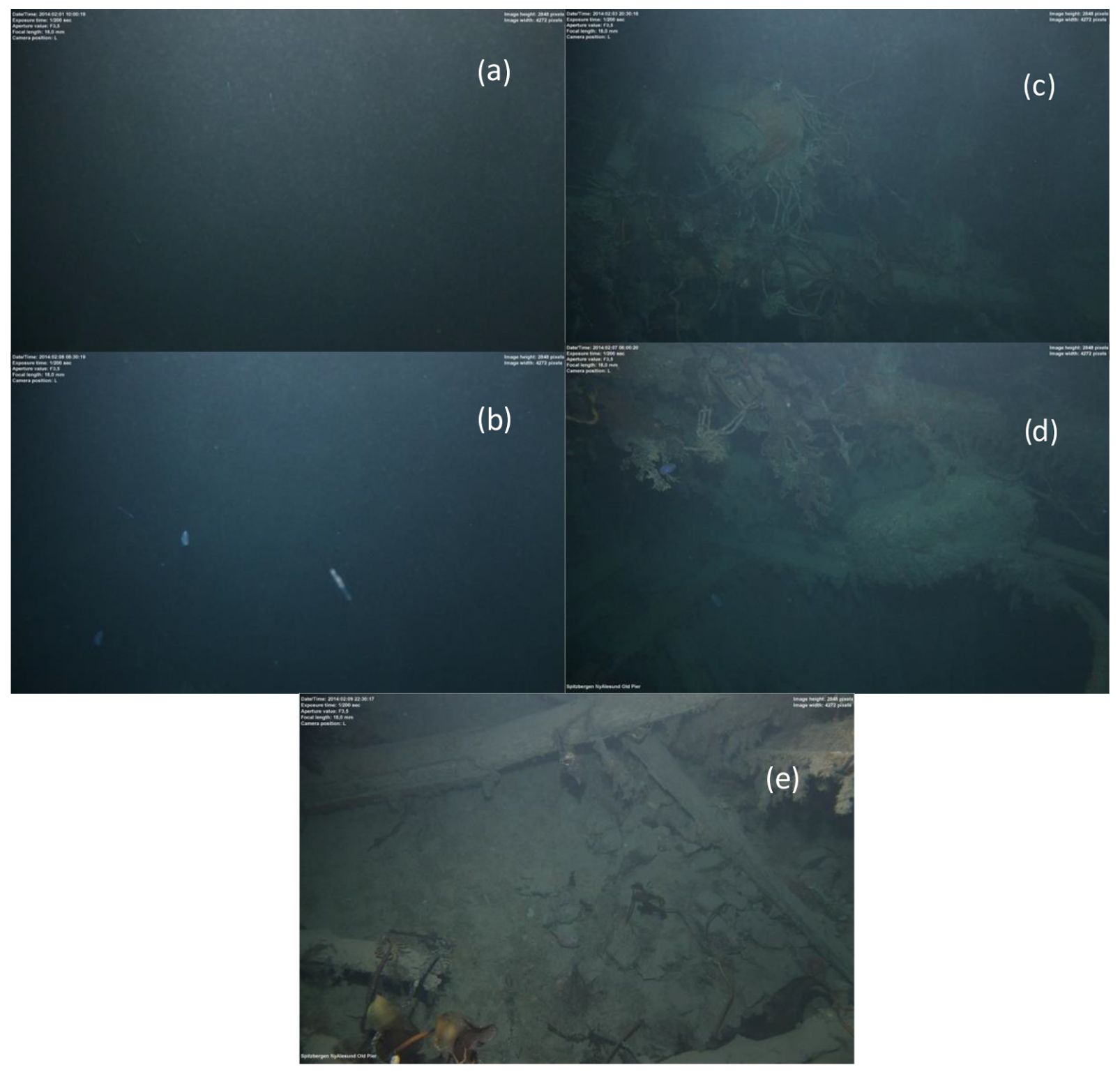

Figure 3. (a, b, c, d, e) View of the RemOs1 stereo-optical system in the five different depth strata. (a) Depth stratum 0-2 m, (b) depth stratum 2-4 m, (c) depth stratum 4-6 m, (d) depth stratum 6-8 m, and depth stratum (e) 8-11 m.

dard deviations per month were calculated based on four or five weekly CPUE values depending on how many weeks a month had. The analysis revealed a distinct seasonal cycle with high specimen abundances during the winter months from December to April, lowest values from May to July, and a second smaller peak in August and September. Figure 5 (lower panel) shows the same monthly abundance values but separated by groups of organisms. Ten different groups of organisms were identified over the year, namely, appendicularia, benthic crustacea, birds, chaetognaths, fish, jellyfish, molluscs, pelagic crustaceans, polychaets, and pteropods. From these groups, six occurred in higher abundances, at least during a certain phase of the year (benthic crustacean, fish, jellyfish, appendicularia, chaetognaths, and pteropods).

During the winter-spring peak, benthic crustaceans had the highest share of the total species abundances, followed by jellyfish, pteropods, and fish (Fig. 5, lower panel). In contrast, the summer-autumn peak was almost completely formed by appendicularia and a smaller share of fish.

When analysing the winter-spring phase (DecemberMarch) and the summer-autumn phase (August-October) separately and in detail, a strong spatial separation of the winter-spring and summer-autumn communities emerged with respect to the position in the water column (Fig. 6). While the overall share of the winter-spring community was 

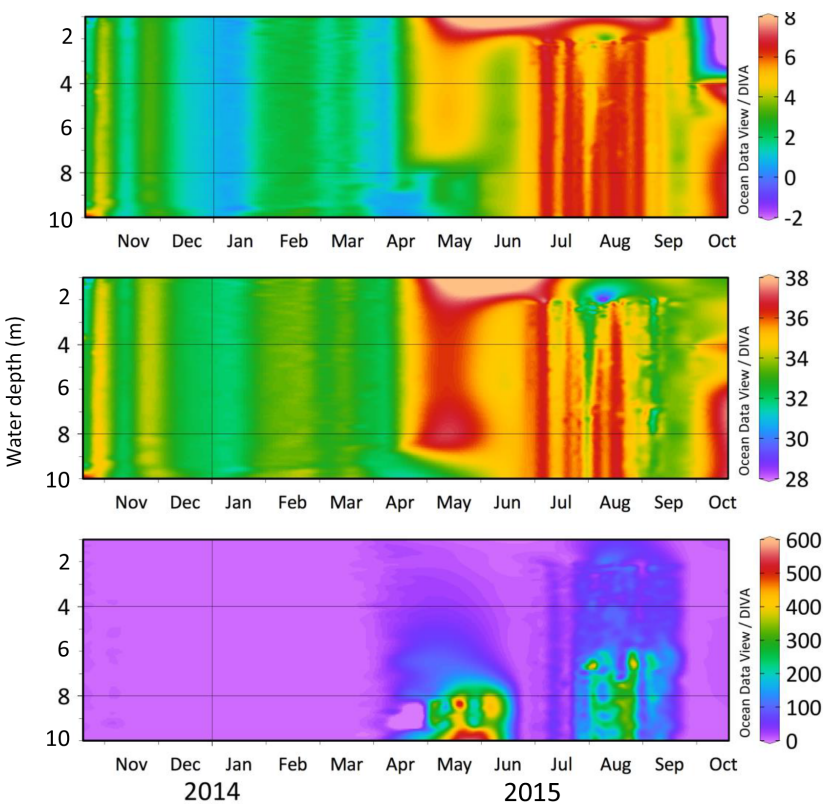

Figure 4. Temporal-spatial pattern in water temperature $\left({ }^{\circ} \mathrm{C}-\right.$ upper panel), salinity (PSU - central panel), and turbidity (FTU lower panel) from October 2013 to October 2014 for the depth range 1 to $11 \mathrm{~m}$ based on daily vertical CTD profiles from 10 to $1 \mathrm{~m}$ and the FerryBox data from $11 \mathrm{~m}$ (fixed inlet).
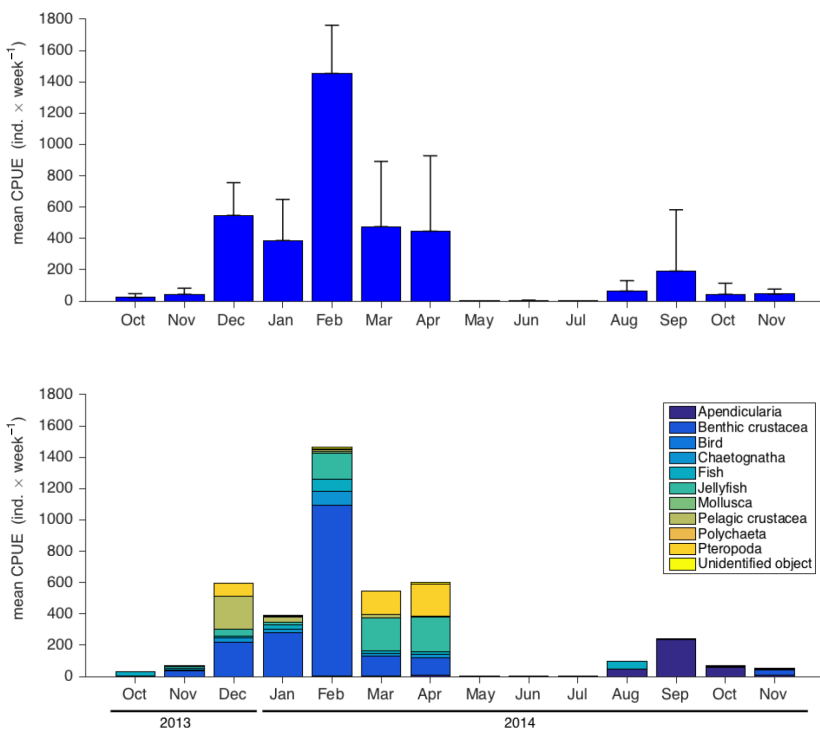

Figure 5. Seasonal cycle in total species abundance (upper panel) and species composition (lower panel) pooled per month of the year. For details with respect to "Catch per unit effort", see the text.

benthic or benthic-associated except for the jellyfish, this benthic-associated community was almost completely missing in the summer and autumn, except for a small share of fish.

Except for appendicularia, all of the other highly abundant species were identified to the species level if possible. Fig-
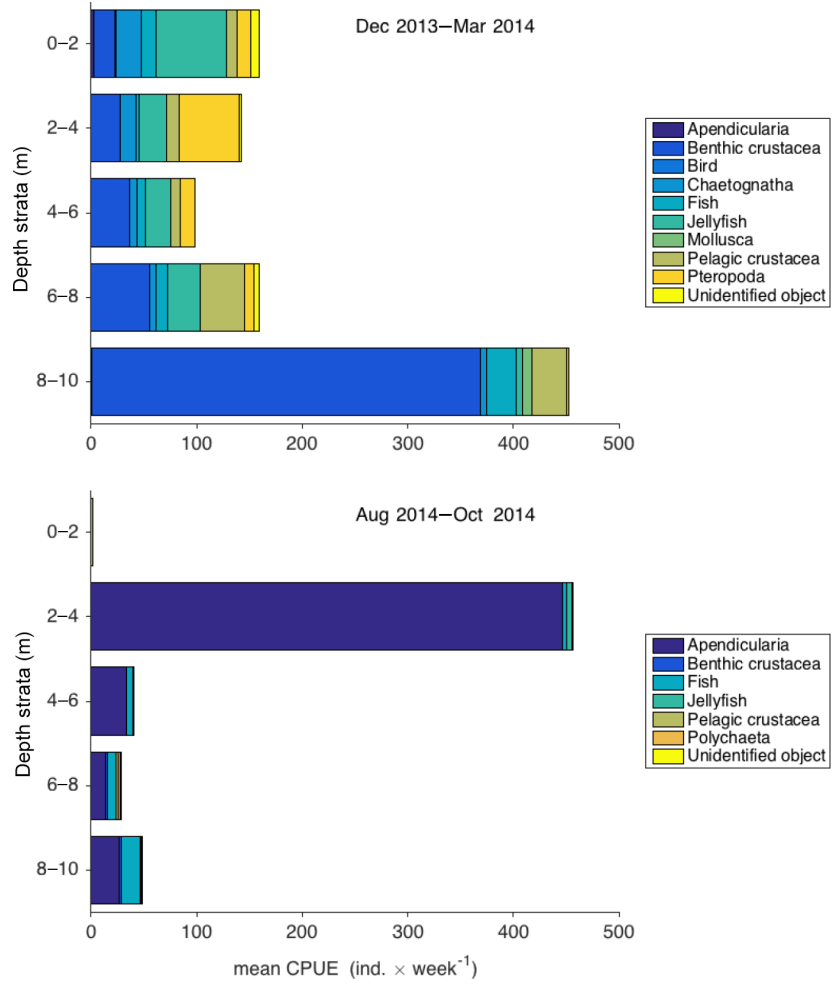

Figure 6. Vertical distribution of the different species groups over the water columns. For details with respect to "Catch per unit effort", see the text.

ure 7 shows the species composition of benthic crustaceans (upper panel), fish (middle panel), and jellyfish (lower panel). The analysis revealed that approximately $90 \%$ of the benthic crustaceans identified over the year were made up of a single species, the great spider crab Hyas araneus (L.). In addition, hermit crabs (Paguridae) were also found occasionally as well as benthic living decapod crustaceans, which most probably belonged to the mysid species Mysis oculata (approximately $10 \%$ share). Hyas araneus, however, clearly dominated the benthic decapod community, especially in the winter month of February, when a mass invasion of this species was observed in the area.

A similar uniform pattern was observed in fish (Fig. 7 middle panel); $81 \%$ of the fish on the images were classified as cod of either one of the two species Gadus morhua (L.) $(50 \%)$ or Bodeogadus saida (L.) (31\%). The differentiation of these two species, however, has to be perceived critically because it was based on coloration, which is especially problematic in young specimens. For all the subsequent analyses, we pooled these two fish species and summarized them under "Gadidae".

The most diverse groups over the year were the jellyfish (Fig. 7 - lower panel). A total of nine different species plus one class "unidentified" were found. Integrated over the year, the most dominant jellyfish species $(57 \%)$ belonged to the 

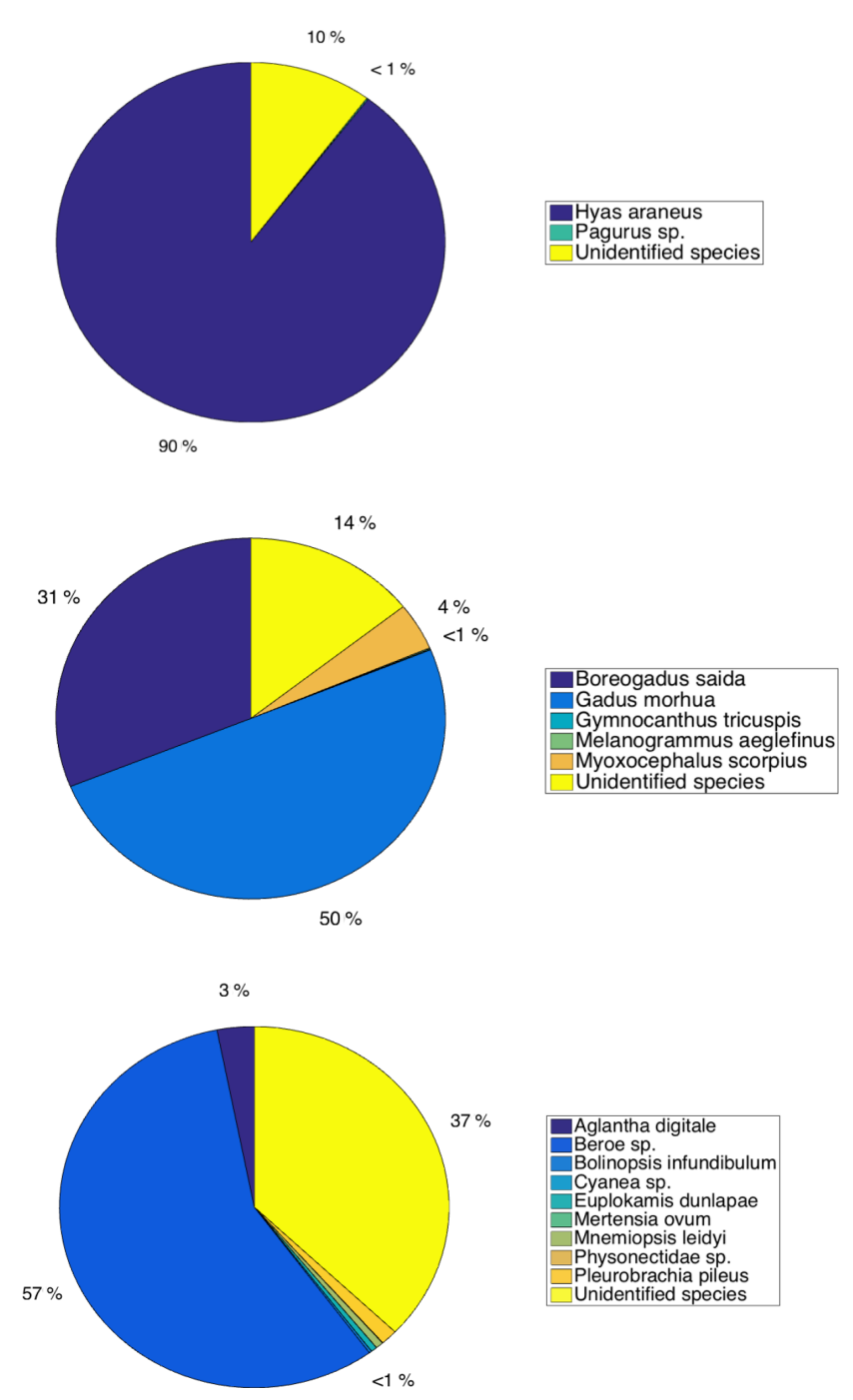

Figure 7. Percent distribution of the different species within the different biota groups. For details, see the text.

group Beroe sp., followed by Aglantha digitale (8\%) and Pleurobrachia pileus (5\%). All the other identified species (Physonectidae sp., Mnemiopsis leidyi, Mertensia ovum, Euplocamis dunlapa, Cyanea sp., Bolinopsis iunfundibulum, and Aglantha digitale) occurred in abundances with a total share of $<1 \%$. Unfortunately, $37 \%$ of the jellyfish could not be clearly identified to the species level and, therefore, had to be left unidentified. These species most certainly did not belong to the above-mentioned identified species, which indicates that the jellyfish diversity in this area is even higher.

For the dominant species of the six major biota groups (benthic crustacean, fish, jellyfish, appendicularia, chaetognaths, and pteropods), the body sizes were measured for up to 200 randomly selected specimens per month (if available). In benthic crustaceans, the carapax length from the tip of the rostrum to the end of the telson (in a normal body position) was measured; for fish, the standard length; for jellyfish, the largest body dimension (either longitudinal or transversal); and for chaetognaths and pteropods, the longitudinal body axes were measured. The system allowed for an accuracy in length measurements of approximately $3 \%$ (Wehkamp and Fischer, 2014). Figures 8 to 10 show the size-frequency distributions of the six measured groups per month over the seasonal cycle from October 2013 to November 2014. As the most abundant species during the winter months, November to March, Hyas araneus showed an average carapax length of between 50 and $100 \mathrm{~mm}$ (Fig. 8 - upper panel) with no temporal trend over the months. However, in November and December 2013, larger animals with a carapax length of up to $180 \mathrm{~mm}$ also appeared in the area, which disappeared during the spring and re-appeared again 1 year later in November 2014.

In contrast, in the pooled species group "Gadidae", a clear increase in the average length over the months was observed (Fig. 8 - lower panel). Starting in November 2013, the young-of-the-year (YOY) cohort appeared in the area with an average standard length between 70 and $100 \mathrm{~mm}$. This 2013 cohort stayed in the area until March 2014, when they reached an average length between 100 and $125 \mathrm{~mm}$. After this time, no more cod was observed in the area over the spring and summer until then next YOY cohort appeared for a short time in higher abundances in August 2014 with an average standard length between 40 and $70 \mathrm{~mm}$ (mean $\pm \mathrm{SD}=65 \pm 16 \mathrm{~mm}$ ). After this time, no more YOY cod could be observed in the shallow area. Instead, larger cod of up to $300 \mathrm{~mm}$ were observed sporadically in the shallow waters (Fig. 8 - lower panel, September-October 2014).

All of the other species that occurred in higher abundances in the shallow areas around NyÅlesund belonged to the pelagic community. In jellyfish, the ctenophore Beroe sp. made up a major share of the planktonic community and appeared with higher abundances in the winter months, November to April, but with only a few specimens during the summer months. For Beroe sp., no temporal size distribution pattern was observed over the months (Fig. 9 - upper panel). The highest abundances were observed in February, with an average size in the longitudinal direction of $45 \mathrm{~mm}$ spanning from 10 to $75 \mathrm{~mm}$ with average values of $32 \pm 8 \mathrm{~mm}$ (mean $\pm \mathrm{SD}$ ). Jellyfish occurred with the highest abundances in the shallow-most water layer between 0 and $2 \mathrm{~m}$ and in only lower abundance in the water columns between 2 and $8 \mathrm{~m}$. In the deepest water layer close to the bottom, the abundances of Beroe sp. were the significantly lowest over the entire water column $\left(\mathrm{LR} \chi^{2}=105, \mathrm{~d} f=3, p<0.001\right)$.

Another temporally dominant but more agile species compared to the jellyfish were the chaetognaths. This group also occurred with the highest abundances during the winter months (Fig. 9 - lower panel) and were also completely missing during the polar summer. Compared to the jellyfish, however, which were almost equally distributed over the water column except for the deepest stratum, Chaetognath occurred highly stratified in the water columns, with the high- 

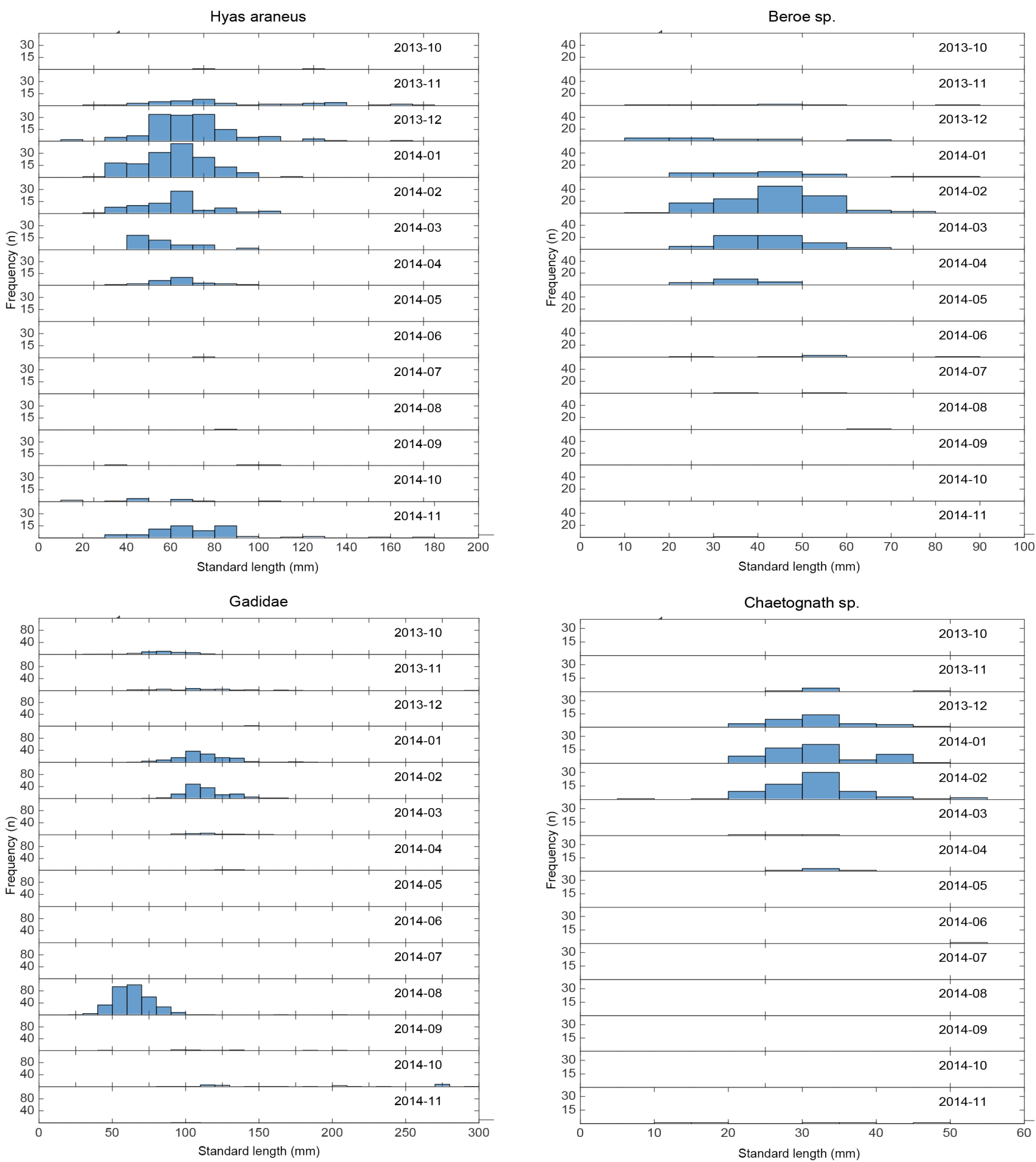

Figure 8. Length-frequency distributions of selected species or species groups (see panels) over the seasonal cycle.

est abundances in the 2-4 $\mathrm{m}$ depth layer; no specimen was found in the surface layer shallow than $2 \mathrm{~m}$, and significantly lower abundances were also found in the deeper water layers $\left(\mathrm{LR} \chi^{2}=490, \mathrm{~d} f=3, p<0.001\right)$. With lengths between 20

Figure 9. Length-frequency distributions of selected species or groups (see panels) over the seasonal cycle.

and $50 \mathrm{~mm}$ (mean $\pm \mathrm{SD}=32 \pm 8 \mathrm{~mm}$ ), chaetognaths formed a major part of the pelagic winter community in the shallow areas. A detailed image based on species identification 

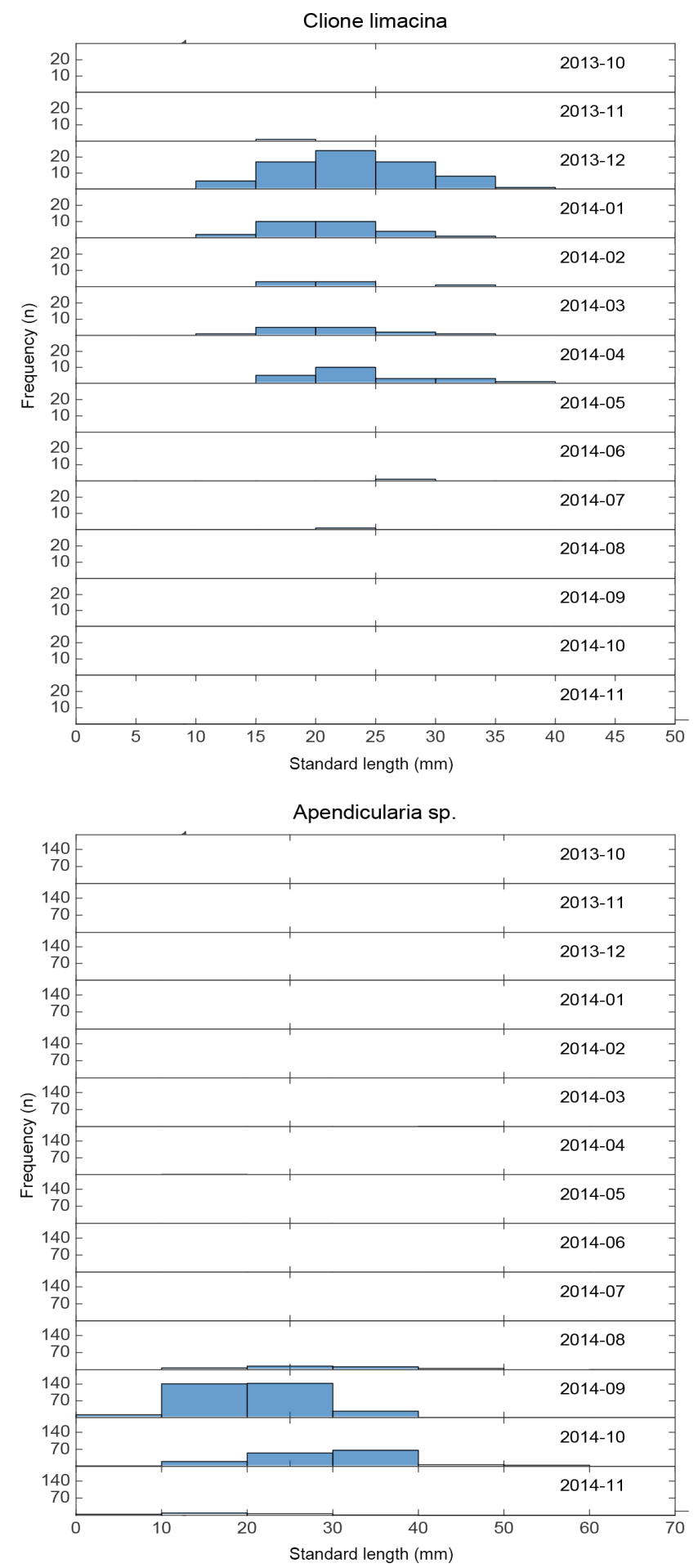

Figure 10. Length-frequency distributions of selected species (see panels) over the seasonal cycle.

as well as on the size distribution of the observed chaetognaths suggests that the majority of the observed specimens belong to the species Parasagitta elegans (Verrill, 1873).
Temporally, almost synchronized with the chaetognaths, pteropods (Fig. 10 - upper panel) also occurred in the water column and were observed in higher abundances until April. On the images, only Clione limacina was observed with body sizes from 10 to $40 \mathrm{~mm}$ and a mean size of $23.1 \pm 5.5 \mathrm{~mm}$ (mean $\pm \mathrm{SD}$ ). Similar to the above-described chaetognaths and jellyfish, Clione limacine also occurred highly stratified in the water column, with a peak abundance in the 2 $4 \mathrm{~m}$ depth layer and significantly lower abundances both in the surface layer and in deeper water strata $\left(\operatorname{LR} \chi^{2}=143\right.$, $\mathrm{d} f=4, p<0.001$ ).

The only species that reached higher abundances not in winter but during the summer months were the appendicularia (Fig. 10 - lower panel). Especially during the months August to October a mass invasion of appendicularia in the upper water columns was observed. As for the other pelagic species, those higher abundances were mainly observed in the 2 to $4 \mathrm{~m}$ water layer, while no appendicularia were observed in the uppermost layer close to the surface and significantly lower abundances were observed below $4 \mathrm{~m}$ water depth $\left(\operatorname{LR} \chi^{2}=1039, \mathrm{~d} f=3, p<0.001\right)$.

\section{Discussion}

Shallow water areas are well known as important habitats for shallow water fish communities (Reyjol et al., 2005). Due to the often higher structural complexity of shallow coastal waters compared to the deeper parts of the ocean, coastal habitats are often observed as important spawning areas and nursery grounds that form the biological backbone of a diverse and stable benthic and fish community in the associated marine habitats. For the same reason, however, studying higher tropic biota in coastal environments is challenging with regard to a detailed assessment of their temporal and spatial dynamics, especially of mobile communities. The high structural complexity, especially of shallow water hard bottom or reef habitats, often prevents classical ship-supported and space-integrative sampling methods such as trawling or box coring (Brickhill et al., 2005; Fischer et al., 2007a; Wilding et al., 2007). Assessments in these structurally complex environments often require small-scaled and highly specialized "sampling" methodologies often based on optical mapping or imaging technologies operated by divers or ROVs, depending on the water depth. Brickhill et al. (2005), Fischer et al. (2007b), and Wehkamp and Fischer (2014) discussed the potential of such techniques specifically for the assessment of fish-habitat relationships in temperate and boreal habitats such as the southern North Sea. They concluded that in these waters, the comparatively restricted transparency of the water, the lower water temperatures, and the harsher weather conditions often result in only short operation times that result in low numbers of freeze-frame sub-samples taken in most studies, preventing a thorough analysis of the specieshabitat relationships due to an insufficiently fine-scale sam- 
pling frequency. These limiting factors, especially of diveroperated in situ video technologies, often lead to extremely high variability in organism counts per frame, with too many zero counts, especially when the target organisms are mobile. This leads to a dramatic loss of statistical power in the subsequent data analysis (Brickhill et al., 2005).

These limitations are even more distinct in polar areas where the diver-supported access to the ecosystem is both temporally restricted and extremely expensive. Sampling structurally complex coastal habitats in polar areas is often only possible during a restricted period of time in the polar summer when light is available and the temperatures allow for in situ methods. Therefore, our knowledge of polar shallow water ecosystems and especially their role as nursery and juvenile habitat is extremely restricted. Most of the recent studies (e.g. Hop et al., 2002, 2012; Svendsen et al., 2002) in our addressed study area have been conducted during summer, when the fjord system is accessible by research vessels. Although the summer productive period is of great importance for Arctic ecosystems, several crucial processes (e.g. reproduction) take place during other seasons and especially during the polar winter. During these times, however, almost no information is available in most Arctic fjord systems (Kwasniewski, 2003). Understanding polar ecosystems in the context of global warming and expected or already observed ecosystem changes (Müller et al., 2011; Bartsch et al., 2016) is, however, crucial for thoroughly understanding the ecosystem behaviour in polar areas.

In this study, we do not provide results from experimental work in Kongsfjorden based on discrete studies with a clear short-term ecological hypothesis. In contrast, we provide data from a 1-year long quantitative assessment of hydrographic parameters together with quantitative data on the macrobiota community assessed by a remote controlled cable-connected underwater observatory installed in a typical shallow water habitat in the Kongsfjorden. Using a remote controlled vertical profiling system, we were able to continuously assess temperature, salinity, turbidity, and other hydrographic parameters together with the shallow water macrobiotic community over the entire water column from the benthic over the epi-benthic to the pelagic realm at a high temporal resolution. To our knowledge, this is the first dataset both from Kongsfjorden and from the entire Arctic that reveals such a year-round assessment of the shallow water macrobiotic community together with the quantitative data of the water temperature, salinity, and turbidity and, therefore, allows a deeper insight into the coupling of the seasonal dynamics of the biology and the hydrography compared to pure summer studies. The data reveal a distinct winter community in the fjords' shallow water ecosystem, which by far exceeds the summer community in both abundance and species diversity. Although we have not yet calculated biomass per $\mathrm{m}^{3}$ for the assessed species, our data clearly show that the species abundance and species richness are highest during the polar winter that begins in December when no more light is available under water. During this time, except for the appendicularia, most species, including fish (mainly gadids of the species Gadus morhua and Boerogadus saida), jellyfish (mainly Beroe sp.), chaetognaths (Parasagitta elegans), pteropods (Clione limacina), and smaller benthic and epi-benthic crustaceans (most possibly Mysis oculata, C. Buchholz, personal communication, 2016) invade the shallow water zone and build up highest abundances. During this study, an overall peak abundance was observed in February when the common sea spider Hyas araneus clearly dominated the community in numbers and biomass for a short time. Only 1 month later in March, however, Hyas araneus almost completely disappeared when fish, jellyfish, and pteropods formed the predominant community with respect to the overall abundances. The "winter" community persisted until April and then almost vanished. The time of the winter community "disappearance" highly corresponds to the increasing availability of light under water. Although sunlight is available at NyÅlesund again already during the middle of March (http://www. awipev.eu/awipev-observatories/current-weather/), the inclination angle of the light is still low until April, so that only a small fraction of the sunlight penetrates the water column (personal observation). However, to really correlate the presence of the "winter community" with the availability of light underwater, discrete measurements of the light intensity and light quality are necessary in the different depth strata to reveal whether light is an ultimate factor in the temporal occurrence of the fjords' shallow water winter community or only a proxy associated with another environmental factory. Our data suggest that especially water temperature may also have a significant influence on the spatio-temporal occurrence of the winter community. Our daily sampled temperature profiles clearly show that water temperature in the shallow water areas of Kongsfjorden can change within short times, even in winter, between $<0$ and up to $4^{\circ} \mathrm{C}$. In particular, the peak abundance in the common sea spider Hyas araneus corresponds to the time of higher water temperature during February, and the collapse of the spider abundance occurred when the water temperatures decreased from $4{ }^{\circ} \mathrm{C}$ to only approximately $2{ }^{\circ} \mathrm{C}$ again. A similar temporal pattern could also be observed in the overall species abundance in April, when a short cold phase in the water temperature occurred. However, these seemingly corresponding changes in the biotic community and the changes in the abiotic environments may also be purely by chance, and we do not know yet whether there are functional relationships between these observations. The permanent installation of the cabled underwater observatory at NyÅlesund allows us to formulate and test such a hypothesis of a persisting shallow water "winter community" in the fjord system as well as the hypothesized controlling or at least affecting abiotic factors.

Our data additionally reveal another distinct community during the summer months when the temperatures increased up to $8^{\circ} \mathrm{C}$ in the fjord. Then, appendicularia occurred in higher abundances for a restricted time, i.e. from August to 
October, in the shallow water with a peak in abundances in September. In contrast to the winter community, which was mainly benthic or at least benthos-associated, this summer community was almost completely dominated by a single appendicularia species, most certainly belonging to the genus Oikopleura sp. (Dahms et al., 2015).

Besides appendicularia, juvenile cod fish were also found in September in the deeper littoral water layers closely associated with benthic habitats. The detailed length-frequency analysis of this cohort reveals that these fish were the YOY offspring of the same year (YOY cohort 2014) with an average standard length of $65 \pm 16 \mathrm{~mm}$. The data also reveal that these fish seem to stay in the littoral zone (even though the overall abundances strongly decreased over winter) and continuously grow and reach an average standard length of 100 to $125 \mathrm{~mm}$ in February-March at age class 1, when they seem to quantitatively leave the shallow water habitats. This outcome indicates a complex migration pattern of YOY cod in this area with a short winter phase in the littoral zone of the fjord system of Spitzbergen and a later migration towards deeper or offshore habitats as adults. Such temporally restricted shallow water phases have been observed already for several other cod species, especially during their juvenile phase (Pihl, 1982). This has been regarded as a juvenile behaviour to prevent predation by older conspecifics in the deeper adult habitats (Ruiz et al., 1993) as well as an improvement in the foraging efficiency of the juveniles during their non-piscivore microzoobenthic benthic feeding phase (Pihl, 1982).

In contrast to the clearly visible seasonal growth pattern in the cod species, no distinct growth could be observed in any of the other species, even in the highly abundant common sea spider, which showed a persisting size range between approximately 50 and $80 \mathrm{~mm}$ during all the winter months, except for the month of November in both years, when larger animals between 120 and $180 \mathrm{~m}$ were observed in the area, even though in much lower abundances.

As clearly stated before, this study does not provide a singular hypothesis-driven question; instead, it focuses on a basic assessment of the temporal (and with respect to the water column also spatial) pattern in the macrobiota community distribution and possible hydrographic factors that influence the shallow water biota. The results of this study are by far incomplete and only represent a 1-year study at a specific site in the Kongsfjorden ecosystem, which may or may not be representative of the shallow water community of this area. However, the study presents a continuous year-round dataset at a temporal resolution of 1 week, which is, to our knowledge, not available in any other fjord system, and especially not in the Arctic environment, where winter data are missing at almost every level. However, even though the data provide a unique year-round insight into a polar shallow water fjord community, we can assume that the technology used here has a certain bias with respect to species selectivity. Therefore, these data have to be taken with care. For instance, com- paring our stereo-optically assessed fish data with data from classical sampling devices in Kongsfjord (Brand and Fischer, 2016; Hop et al., 2002; Renaud et al., 2011) or even with sporadic diver observations (Brand and Fischer, 2016; Hop et al., 2002), it becomes clear that our optical sensors are also species selective. Brand and Fischer (2016) for example reported for the summer month a distinct occurrence of the benthic sculpin Myoxocephalus scorpius, a typical temperate and highly camouflaged benthic fish species in fykenet catches. Although we detected Myoxocephalus scorpius during summer also on the stereoscopic images, the overall abundance remained quite low. Unfortunately, the fykenet catches of Brand and Fischer (2016), as with most other available marine studies of the fjord, are only available for the polar summer months, when our stereo-optical data revealed the lowest overall biota abundance at all. However, taking into account that fyke nets are highly time integrative and catch fish only directly at the bottom, the fyke-net and optical data may be complementary rather than contradictory. In the study of Brand and Fischer (2016), fyke nets with a mesh size of $12 \mathrm{~mm}$ and a steering net of $18 \mathrm{~mm}$ were used. This type of net gear is highly selective for strictly benthic fish species with a high potential of entanglement, such as sculpins. In contrast, a stereo-optical method is most probably less selective for benthic highly camouflaged fish species and may significantly underestimate fish with these characteristics.

Instead, our overall image assessment procedure was thoroughly performed by two different persons and showed similar results with respect to the quantitative detection of even small benthic mysids. Therefore, we assume that we would have also detected sculpins if available in higher abundances and thus conclude that the quantitative relation of the average abundance between the major fish species found on the images might be more precise, as found in the fyke net catches. This outcome seems to be supported also by the available diver observations in that area, at least during summer. Hop et al. (2002) and Renaud et al. (2011) both reported the cod species Gadus morhua as one of the most abundant species in the area, which would be in accordance with our findings. Nevertheless, the comparison of these two methods shows that there is a large uncertainty with respect to the methodological approach that should be used in future studies. Furthermore, our in situ optical methods allow for a low-invasive abundance estimate, for a precise length-frequency analysis of the mapped fish, and also for a continuous year-round assessment of the community. However, it does not allow for further investigations such as stomach content analysis and precise aging based on scale or otolith analysis. If we manage to combine such continuous hydrographic and community observations using cable-connected observatories with classical ground truthing fishing or sampling methods, we may reduce our scientific fishing effort to a limited number of specimens, which are needed for specific detailed analysis such as stomach content and otolith-based aging, and obtain 
the required more invasive stock abundance and growth data via non-invasive optical methods. These approaches may finally enable the reduction of our fishing effort without losing the required data density and therefore contribute to the increasing scientific demand of a resource conservative science also in fish and community ecology, especially in ecologically sensitive areas such as the polar fjords or marine protected areas.

\section{Next steps and needs}

In addition to the ecological and hydrographical results from the Kongsfjorden ecosystem presented here, the study demonstrates the advantages of permanently operated cabled observatory technology - especially when combined with other research methods in a multidisciplinary approach integrating biology with the understanding of the physical environment. Cabled observatories with continuous power supply and network access allow the use of state of the art IT technology and smart-monitoring approaches under water. These are often not applicable in mooring-based sensor technology because no feedback to the operator is possible and therefore the researcher himself cannot react to specific environmental situations during the measuring process. Furthermore, complex sensor systems like profiling videos or stereo-imaging systems often cannot be operated unsupervised for longer times because the controlling software is either too complex, the power consumption is too high, or the required test and development phases for unsupervised operation of such systems are too long and therefore too expensive. Cabled observatories with permanent access, power supply, and systems control allow even complex sensor systems to be operated for longer periods because in case of failures, the system can give an alert to an operator elsewhere to request remote control and if necessary sensor reset. Based on our experiences with the cabled observatory in Svalbard, we assume that such underwater research facilities, if operated within an international and well-focused research strategy, may significantly promote our knowledge, especially in remote and sensitive areas like the polar regions.

Data availability. Supplementary data are available at doi:10.1594/PANGAEA.874141 (Fischer, 2017).

Competing interests. The authors declare that they have no conflict of interest.

Acknowledgements. We express our strong thanks to the AWIPEV staff, i.e. Rene Buergi and Verena Mohaupt, who made the continuous operation of the underwater observatory in this remote site possible. We furthermore want to thank the numerous divers from the AWI dive group, who did great work during our maintenance missions, as well as María Algueró Muñiz and Cornelia Bucholz for species identification of the jellyfish and the mysids. Special thanks also go to Christian Wiencke, who strongly supported the idea of a cabled underwater observatory at AWIPEV in the initialization phase. Furthermore, we want to explicitly express our thanks to the two reviewers, who gave us great support during the review process.

This work has been supported through the Coastal Observing System for Northern and Arctic Seas (COSYNA).

The article processing charges for this open-access

publication were covered by a Research

Centre of the Helmholtz Association.

Edited by: P. Testor

Reviewed by: C. Wiencke and I. Puillat-Felix

\section{References}

Aguzzi, J., Mànuel, A., Condal, F., Guillén, J., Nogueras, M., Del Rio, J., Costa, C., Menesatti, P., Puig, P., Sardà, F., Toma, D., and Palanques, A.: The New Seafloor Observatory (OBSEA) for Remote and Long-Term Coastal Ecosystem Monitoring, Sensors, 11, 5850-5872, doi:10.3390/s110605850, 2011.

Bartsch, I., Paar, M., Fredriksen, S., Schwanitz, M., Daniel, C., Hop, H., and Wiencke, C.: Changes in kelp forest biomass and depth distribution in Kongsfjorden, Svalbard, between 1996-1998 and 2012-2014 reflect Arctic warming, Polar Biol., 39, 2021-2036, doi:10.1007/s00300-015-1870-1, 2016.

Brand, M. and Fischer, P.: Species composition and abundance of the shallow water fish community of Kongsfjorden, Svalbard, Polar Biol., 1-13, doi:10.1007/s00300-016-2022-y, 2016.

Brickhill, M. J., Lee, S. Y., and Connolly, R. M.: Fishes associated with artificial reefs: attributing changes to attraction or production using novel approaches, J. Fish Biol., 67, 53-71, 2005.

Buckland, S. T., Magurran, A. E., Green, R. E., and Fewster, R. M.: Monitoring change in biodiversity through composite indices, Philos. T. R. Soc. B, 360, 243-254, doi:10.1098/rstb.2004.1589, 2005.

Cottier, F., Tverberg, V., Inall, M., Svendsen, H., Nilsen, F., and Griffiths, C.: Water mass modification in an Arctic fjord through cross-shelf exchange: The seasonal hydrography of Kongsfjorden, Svalbard, J. Geophys. Res.-Oceans, 110, C12005, doi:10.1029/2004JC002757, 2005.

Dahms, H.-U., Joo, H.-M., Lee, J. H., Yun, M. S., Ahn, S. H., and Lee, S. H.: Demersally drifting invertebrates from Kongsfjorden, Svalbård (Arctic Ocean) - a comparison of catches from drift-pump and drift-nets, Ocean Science Journal, 50, 639-648, doi:10.1007/s12601-015-0058-5, 2015.

Fischer, P.: Fish, macroinvertebrate and hydrographic data including ctd profiling data from the shallow water area of Kongsfjord, Svalbard from 2013 to 2014, PANGAEA, doi:10.1594/PANGAEA.874141, 2017.

Fischer, P. and Eckmann, R.: Seasonal changes in fish abundance, biomass and species richness in the littoral zone of a large European lake, Lake Constance, Germany, Arch. Hydrobiol., 139, 433-448, 1997a.

Fischer, P. and Eckmann, R.: Spatial distribution of littoral fish species in a large European lake, Lake Constance, Germany, Arch. Hydrobiol., 140, 91-116, 1997b. 
Fischer, P., Weber, A., Heine, G., and Weber, H.: Habitat structure and fish: assessing the role of habitat complexity for fish using a small, semiportable, 3-D underwater observatory, Limnol. Oceanogr.-Meth., 5, 250-262, 2007.

Hegseth, E. N. and Tverberg, V.: Effect of Atlantic water inflow on timing of the phytoplankton spring bloom in a high Arctic fjord (Kongsfjorden, Svalbard), J. Marine Syst., 113, 94-105, doi:10.1016/j.jmarsys.2013.01.003, 2013.

Hop, H., Pearson, T., Hegseth, E. N., Kovacs, K. M., Wiencke, C., Kwasniewski, S., Eiane, K., Mehlum, F., Gulliksen, B., Wlodarska-Kowalczuk, M., Lydersen, C., Weslawski, J. M., Cochrane, S., Gabrielsen, G. W., Leakey, R. J. G., Lønne, O. J., Zajaczkowski, M., Falk-Petersen, S., Kendall, M., Wängberg, S.-Å., Bischof, K., Voronkov, A. Y., Kovaltchouk, N. A., Wiktor, J., Poltermann, M., Prisco, G., Papucci, C., and Gerland, S.: The marine ecosystem of Kongsfjorden, Svalbard, Polar Res., 21, 167-208, doi:10.1111/j.1751-8369.2002.tb00073.x, 2002.

Hop, H., Wiencke, C., Vögele, B., and Kovaltchouk, N. A.: Species composition, zonation, and biomass of marine benthic macroalgae in Kongsfjorden, Svalbard, Bot. Mar., 55, , 399-414, doi:10.1515/bot-2012-0097, 2012.

Jørgensen, L. L. and Gulliksen, B.: Rocky bottom fauna in arctic Kongsfjord (Svalbard) studied by means of suction sampling and photography, Polar Biol., 24, 113-121, doi:10.1007/s003000000182, 2001.

Kwasniewski, S.: Distribution of Calanus species in Kongsfjorden, a glacial fjord in Svalbard, J. Plankton Res., 25, 1-20, doi:10.1093/plankt/25.1.1, 2003.

Müller, R., Bartsch, I., Laepple, T., and Wiencke, C.: Impact of oceanic warming on the distribution of seaweeds in polar and cold-temperate waters, in: Biology of Polar benthic algae, de Gruyter, edited by: Wiencke, C., 237-270, 2011.

Norwegian Polar Institute (2014): Kartdata Svalbard 1:100000 (S100 Kartdata) / Map Data [Data set], Norwegian Polar Institute, https://doi.org/10.21334/npolar.2014.645336c7, last access: 31 March 2017.

Paar, M., Voronkov, A., Hop, H., Brey, T., Bartsch, I., Schwanitz, M., Wiencke, C., Lebreton, B., Asmus, R., and Asmus, H.: Temporal shift in biomass and production of macrozoobenthos in the macroalgal belt at Hansneset, Kongsfjorden, after 15 years, Polar Biol., 39, 2065-2076, doi:10.1007/s00300-015-1760-6, 2015.

Peterson, B. J., Holmes, R. M., McClelland, J. W., Vörösmarty, C. J., Lammers, R. B., Shiklomanov, A. I., Shiklomanov, I. A., and Rahmstorf, S.: Increasing river discharge to the Arctic Ocean, Science, 298, 2171-2173, doi:10.1126/science.1077445, 2002.

Pihl, L.: Food intake of young cod and flounder in a shallow bay on the Swedish west coast, Neth, J. Sea Res., 15, 419-432, doi:10.1016/0077-7579(82)90068-0, 1982.

Renaud, P., Tessmann, M., Evenset, A., and Christensen, G.: Benthic food-web structure of an Arctic fjord (Kongsfjorden, Svalbard), Mar. Biol. Res., 7, 13-26, doi:10.1080/17451001003671597, 2011.

Reyjol, Y., Fischer, P., Lek, S., Rösch, R., and Eckmann, R.: Studying the spatiotemporal variation of the littoral fish community in a large prealpine lake, using self-organizing mapping, Can. J. Fish. Aquat. Sci., 62, 2294-2302, doi:10.1139/f05-097, 2005.
Ruiz, G. M., Hines, A. H., and Posey, M. H.: Shallow water as a refuge habitat for fish and crustaceans in non-vegetated estuaries: an example from Chesapeake Bay, Mar. Ecol.-Prog. Ser., 99, 16, doi:10.3354/meps099001, 1993.

Stempniewicz, L., Błachowiak-Samołyk, K., and Węsławski, J. M.: Impact of climate change on zooplankton communities, seabird populations and Arctic terrestrial ecosystem - A scenario, DeepSea Res. Pt. II, 54, 2934-2945, doi:10.1016/j.dsr2.2007.08.012, 2007.

Svendsen, H., Beszczynska-Møller, A., Hagen, J. O., Lefauconnier, B., Tverberg, V., Gerland, S., Ørbæk, J. B., Bischof, K., Papucci, C., Zajaczkowski, M., Azzolini, R., Bruland, O., and Wiencke, C.: The physical environment of Kongsfjorden-Krossfjorden, an Arctic fjord system in Svalbard, Polar Res., 21, 133-166, doi:10.3402/polar.v21i1.6479, 2002.

Voronkov, A., Hop, H., and Gulliksen, B.: Diversity of hard-bottom fauna relative to environmental gradients in Kongsfjorden, Svalbard, Polar Res., 32, 11208, doi:10.3402/polar.v32i0.11208, 2013.

Walczowski, W., Piechura, J., Goszczko, I., and Wieczorek, P.: Changes in Atlantic water properties: an important factor in the European Arctic marine climate, ICES J. Mar. Sci., 69, 864-869, doi:10.1093/icesjms/fss068, 2012.

Wehkamp, M. and Fischer, P.: A practical guide to the use of consumer-level digital still cameras for precise stereogrammetric in situ assessments in aquatic environments, Underwater Technol., 32, 111-128, 2014.

Wehkamp, S. and Fischer, P.: Impact of coastal defence structures (tetrapods) on a demersal hard-bottom fish community in the southern North Sea, Mar. Environ. Res., 83, 82-92, doi:10.1016/j.marenvres.2012.10.013, 2013a.

Wehkamp, S. and Fischer, P.: Impact of hard-bottom substrata on the small-scale distribution of fish and decapods in shallow subtidal temperate waters, Helgoland Mar. Res., 67, 59-72, doi:10.1007/s10152-012-0304-5, 2013b.

Wehkamp, S. and Fischer, P.: The impact of coastal defence structures (tetrapods) on decapod crustaceans in the southern North Sea, Mar. Environ. Res., 92, 52-60, doi:10.1016/j.marenvres.2013.08.011, 2013c.

Werner, E. E.: Species Packing and Niche Complementarity in Three Sunfishes, Am. Nat., 111, 553-578, doi:10.1086/283184, 1977.

Wiencke, C.: The coastal ecosystem of Kongsfjorden, Svalbard. Synopsis of biological research performed at the Koldewey Station in the years 1991-2003, edited by: Wiencke, C., Ber. Polarforsch. Meeresforsch., 492, 1-244, 2004.

Wilding, T. A., Rose, C. A., and Downie, M. J.: A novel approach to measuring subtidal habitat complexity, J. Exp. Mar. Biol. Ecol., 353, 279-286, doi:10.1016/j.jembe.2007.10.001, 2007.

Willis, K., Cottier, F., Kwasniewski, S., Wold, A., and FalkPetersen, S.: The influence of advection on zooplankton community composition in an Arctic fjord (Kongsfjorden, Svalbard), J. Marine Syst., 61, 39-54, doi:10.1016/j.jmarsys.2005.11.013, 2006. 